\title{
Midline Meningiomas of the Anterior Skull Base: Surgical Outcomes and a Decision-Making Algorithm for Classic Skull Base Approaches
}

\author{
Amir Kaywan Aftahy ${ }^{1, * \mathbb{C}}$, Melanie Barz ${ }^{1}{ }^{\mathbb{D}}$, Philipp Krauss ${ }^{1}$, Arthur Wagner ${ }^{1}$, Nicole Lange ${ }^{1}$, \\ Alaa Hijazi ${ }^{1}$, Benedikt Wiestler ${ }^{2}\left(\mathbb{D}\right.$, Bernhard Meyer $^{1}{ }^{(\mathbb{D}}$, Chiara Negwer $^{1}$ and Jens Gempt ${ }^{1}(\mathbb{D})$ \\ 1 Department of Neurosurgery, Klinikum Rechts der Isar, School of Medicine, Technical University Munich, \\ 81675 Munich, Germany; Melanie.barz@tum.de (M.B.); philipp.krauss@tum.de (P.K.); \\ arthur.wagner@tum.de (A.W.); Nicole.Lange@tum.de (N.L.); alaa.h@hotmail.de (A.H.); \\ Bernhard.Meyer@tum.de (B.M.); Chiara.Negwer@tum.de (C.N.); Jens.Gempt@tum.de (J.G.) \\ 2 Department of Neuroradiology, Klinikum Rechts der Isar, School of Medicine, Technical University Munich, \\ 81675 Munich, Germany; B.Wiestler@tum.de \\ * Correspondence: kaywan.aftahy@tum.de; Tel.: +49-89-4140-2151; Fax: +49-89-4140-4889
}

Received: 30 August 2020; Accepted: 31 October 2020; Published: 3 November 2020

check for updates

Simple Summary: Resectioning midline meningiomas of the anterior skull base such as olfactory groove, planum sphenoidale, or tuberculum sellae is challenging, and determining the appropriate approach is important. Based on our experience with midline meningiomas, we propose a decision algorithm for choosing suitable transcranial approaches. With dichotomizing classic skull bases approaches into median and lateral ones, we display that median approaches provide satisfactory results for olfactory groove meningiomas, whereas lateral approaches enable sufficient exposure of the visual apparatus for planum sphenoidale meningiomas or tuberculum sellae meningiomas. This manuscript aims to point out the sufficiency and feasibility of classic transcranial techniques.

Abstract: (1) Background: Midline meningiomas such as olfactory groove (OGMs), planum sphenoidale (PSMs), or tuberculum sellae meningiomas (TSMs) are challenging, and determining the appropriate approach is important. We propose a decision algorithm for choosing suitable transcranial approaches. (2) Methods: A retrospective chart review between 06/2007 and 01/2020. Clinical outcomes, radiographic findings, and postoperative complication rates were analyzed with respect to operative approaches. (3) Results: We included 88 patients in the analysis. Of these, 18.2\% (16/88) underwent an interhemispheric approach, 72.7\% (64/88) underwent a pterional/frontolateral/supraorbital approach, 2.3\% (2/88) underwent a unilateral subfrontal approach, and $6.8 \%(6 / 88)$ underwent a bifrontal approach. All OGMs underwent median approaches, along with one PSM. All of the other PSMs and TSMs were resected via lateral approaches. The preoperative tumor volume was $\emptyset 20.2 \pm 27.1 \mathrm{~cm}^{3}$. Median approaches had significantly higher tumor volume but also higher rates of Simpson I resection (75.0\% vs. 34.4\%). An improvement of visual deficits was observed in $34.1 \%$ (30/88). The adverse event rate was $17.0 \%$. Median follow-up was 15.5 months (range 0-112 months). (4) Conclusions: Median approaches provides satisfying results for OGMs, lateral approaches enable sufficient exposure of the visual apparatus for PSMs and TSMs. In proposing a simple decision-making algorithm, the authors found that satisfactory outcomes can be achieved for midline meningiomas.

Keywords: olfactory groove meningioma; planum sphenoidale meningioma; tuberculum sellae meningioma; anterior skull base; operative technique; neurosurgical oncology; transcranial approaches 


\section{Introduction}

Meningiomas of the anterior skull base are complex lesions due to local bone invasion and the invasion of adjacent neural and vascular structures. Skull base meningiomas represent $25 \%$ of all meningiomas [1]. Meningiomas of the midline anterior skull base include tuberculum sellae meningiomas (TSMs) and planum sphenoidale meningiomas (PSMs), representing $5-10 \%$ of all intracranial meningiomas, and olfactory groove meningiomas (OGMs), representing $8-13 \%$ (3-7). The treatment of choice is maximal safe resection to achieve a low Simpson grading, which is still the main predictor for recurrence-free survival in contemporary studies [2,3]. Other treatment modalities include radiation (including proton beam therapy) and devascularization via catheter embolization. Various classic approaches such as the pterional, frontolateral, supraorbital, subfrontal, bifrontal, and interhemispheric approaches have been described as achieving an optimal visualization of the situs [1,3-9]. In addition to these classical approaches, more complex skull-base approaches have been popularized in recent years, including the use of neuroendoscopy $[3,9,10]$.

In this manuscript, we investigate the extent of resection along with the clinical outcomes and adverse events in a large cohort of patients with midline meningiomas of the anterior skull base at a single tertiary center who underwent classic transcranial approaches.

\section{Results}

\subsection{Clinical Baseline Characteristics}

In total, 88 patients (62 (70.4\%) female, $26(29.5 \%)$ male) fulfilled the inclusion criteria and were analyzed. Olfactory dysfunction and psychomotor decline before surgery were present significantly often in patients with OGMs, as compared to patients with other midline meningiomas of the anterior skull base. Patients with TSM showed significantly better preoperative Karnofsky Performance Status Scale (KPSS) than patients with the other entities did, with overall high levels of KPSS but significantly higher rates of visual affection (Table 1).

Table 1. Demographics and preoperative presentation.

\begin{tabular}{|c|c|c|c|c|c|c|c|c|}
\hline & & \multicolumn{2}{|c|}{ OGM (51) } & \multicolumn{2}{|l|}{ PSM (20) } & \multicolumn{2}{|c|}{ TSM (17) } & Total (88) \\
\hline \multicolumn{2}{|c|}{$\begin{array}{c}\text { Median (IQR), } \\
\text { Mean (SD), N (\%) }\end{array}$} & & $p$ & & $p$ & & $p$ & \\
\hline \multicolumn{2}{|c|}{ Age (years) } & $60(54-74)$ & & $62(49-76)$ & & $53(44-60)$ & & $60(50-73)$ \\
\hline \multirow{2}{*}{ Sex } & $0^{7}$ & $19(37.3 \%)$ & & $5(25.0 \%)$ & & $2(11.8 \%)$ & & $26(29.5 \%)$ \\
\hline & q & $32(62.7 \%)$ & & $15(75.0 \%)$ & & $15(88.2 \%)$ & & $62(70.4 \%)$ \\
\hline \multicolumn{2}{|c|}{ Preop. volume $\left(\mathrm{cm}^{3}\right)$} & $27( \pm 27)$ & $\begin{array}{c}0 . \\
011\end{array}$ & $18( \pm 34)$ & & $3( \pm 2)$ & & $20( \pm 27)$ \\
\hline \multicolumn{2}{|c|}{$\begin{array}{c}\text { Preop. } \\
\text { KPSS (\%) }\end{array}$} & $80(80-90)$ & & $90(80-95)$ & & $90(90-100)$ & 0.027 & $90(80-90)$ \\
\hline \multicolumn{2}{|c|}{ Postop. KPSS (\%) } & $90(80-90)$ & & $90(80-100)$ & & $100(90-100)$ & 0.016 & $90(70-90)$ \\
\hline \multicolumn{2}{|c|}{$\begin{array}{l}\text { Hyposmia/ } \\
\text { Anosmia }\end{array}$} & $51(100.0 \%)$ & $<0.01$ & $2(10.0 \%)$ & & 0 & & $53(60.2 \%)$ \\
\hline \multicolumn{2}{|c|}{ Visual affection } & $13(25.5 \%)$ & & $8(40.0 \%)$ & & $10(58.8 \%)$ & 0.036 & $31(35.2 \%)$ \\
\hline \multicolumn{2}{|c|}{ Amaurosis } & 0 & & 0 & & $3(17.6 \%)$ & & $3(3.4 \%)$ \\
\hline \multicolumn{2}{|c|}{ Psychomot. decline } & $17(34.0 \%)$ & 0.012 & $1(5.0 \%)$ & & 0 & & $18(20.5 \%)$ \\
\hline \multicolumn{2}{|c|}{ Vertigo } & $5(9.8 \%)$ & & 0 & & 0 & & $5(5.7 \%)$ \\
\hline \multicolumn{2}{|c|}{ Seizure } & $9(17.6 \%)$ & & 0 & & 0 & & $9(10.2)$ \\
\hline \multicolumn{2}{|c|}{ Hemiparesis } & $2(3.9 \%)$ & & 0 & & 0 & & $2(2.3 \%)$ \\
\hline
\end{tabular}




\subsection{Tumor Characteristics and Approach-Related Findings}

Histopathological analysis showed a WHO I meningioma in 81 cases (92\%), a WHO II meningioma in six $(7 \%)$ cases, and a WHO III meningioma in one case $(1 \%)$. The preoperative tumor volume was $\emptyset 20.2 \pm 27.1 \mathrm{~cm}^{3}$ (OGM $\emptyset 26.6 \pm 26.2 \mathrm{~cm}^{3}$; PSM $\emptyset 17.6 \mathrm{~cm}^{3} \pm 32.8 \mathrm{~cm}^{3}$; TSM $\left.\emptyset 2.6 \mathrm{~cm}^{3} \pm 1.9 \mathrm{~cm}^{3}\right)$. Patients with OGMs showed significantly higher rates of perifocal edema and ethmoid sinus infiltration compared to patients with all other midline meningiomas (Table 1), whereas patients with TSM showed significantly higher levels of optic nerve affection, bony infiltration of the planum sphenoidale, and anterior clinoid process (Table 2).

Table 2. Tumor characteristic and anterior skull base/neurovascular involvement.

\begin{tabular}{|c|c|c|c|c|c|c|c|}
\hline & OGM (51) & $p$ & PSM (20) & $p$ & TSM (17) & $p$ & Total (88) \\
\hline Calcification & $14(27.5 \%)$ & & $5(25.0 \%)$ & & $2(11.8 \%)$ & & $21(23.9 \%)$ \\
\hline Perifocal edema & $30(58.8 \%)$ & $<0.01$ & $7(35.0 \%)$ & & 0 & & $37(42.0 \%)$ \\
\hline $\begin{array}{l}\text { Ethmoid bone/cribrose } \\
\text { plate infiltration }\end{array}$ & $26(51.0 \%)$ & 0.001 & $1(5.0 \%)$ & & $2(11.8 \%)$ & & $29(33.0 \%)$ \\
\hline $\begin{array}{c}\text { Pituitary stalk } \\
\text { deviation/affection }\end{array}$ & $6(11.8 \%)$ & & 0 & & 0 & & $6(6.8 \%)$ \\
\hline $\begin{array}{c}\text { Frontal } \\
\text { sinus/planum/sphenoid } \\
\text { destruction }\end{array}$ & $9(17.6 \%)$ & & $3(15.0 \%)$ & & $5(29.4 \%)$ & 0.037 & $17(19.3 \%)$ \\
\hline $\begin{array}{l}\text { Orbit/optic nerve } \\
\text { affection }\end{array}$ & $11(21.6 \%)$ & & $9(45.0 \%)$ & & $16(94.1 \%)$ & $<0.01$ & $36(40.9 \%)$ \\
\hline $\begin{array}{c}\text { ACOMA/MCA/ACA } \\
\text { involvement }\end{array}$ & $12(23.5 \%)$ & & $6(30.0 \%)$ & & $5(29.4 \%)$ & & $23(26.1 \%)$ \\
\hline $\begin{array}{l}\text { Anterior clinoid } \\
\text { infiltration }\end{array}$ & 0 & & $2(10.0 \%)$ & & $10(58.8 \%)$ & $<0.01$ & $12(13.6 \%)$ \\
\hline
\end{tabular}

All median approaches were performed in patients with OGMs (frontal interhemispheric, $\mathrm{n}=16$; subfrontal, $n=2$; bifrontal, $n=5$ ), along with one patient with PSM (bifrontal, $n=1$ ), whereas all other PSMs $(n=19)$ and all TSMs $(n=17)$ were resected via lateral approaches (pterional, $n=33$; frontolateral, $\mathrm{n}=28$; supraorbital, $n=3$ ). The tumor volume in patients who received resection via median approaches (MAs) was significantly larger compared to that of tumors approached via lateral approaches (LAs) (MA: $38.0 \pm 38.3 \mathrm{~cm}^{3}$ vs. LA $12.8 \pm 16.5 \mathrm{~cm}^{3} ; p<0.001$ ). Nevertheless, the extent of resection in tumors resected via median approaches (Simpson I 75.0\%, Simpson II: $25.0 \%$ ) was significantly better according to the Simpson grading compared to tumors resected via lateral approaches (Simpson 1 34.4\%; Simpson 2 60.9\%; Simpson 3: 4.7) $(p<0.001)$.

\subsection{Functional Outcome}

The median follow-up was 15.5 months (range 0-112 months), and the median postoperative KPSS was 90\% (range 70-90\%). Oculomotor nerve palsy appeared in 3.4\% (3/88) (PSM 10.0\%, 2/20; TSM 5.9\%, 1/17) of patients and hemiparesis appeared in 1.1\% (1/88) (OGM 2.0\%, 1/51) of patients. Postoperative transient psychomotoric decline occurred in 6.8\% (6/88) (OGM 9.8\%, 5/51; PSM 10.0\%, $2 / 20$ ) of patients and hypopituitarism requiring lasting substitution in 2.3\% (2/88) (TSM 11.8\%, 2/17) of patients. Rates of psychomotoric decline were significantly higher after a frontal interhemispheric approach (OR 14.4; 95\% CI, 2.3292-89.0260, $p=0.004$ ). Preoperative visual deficits improved in 34.1\% (30/88) of patients (OGM in 29.4\% (15/51) of patients, PSM in 25.0\% (5/20) of patients, and TSM in 58.8\% $(10 / 17))$ (Table 3). 
Table 3. Postoperative functional outcome and complications.

\begin{tabular}{ccccc}
\hline & OGM (51) & PSM (20) & TSM (17) & Total (88) \\
\hline Postoperative new visual deficits & $4(7.8 \%)$ & $2(10.0 \%)$ & 0 & $6(6.8 \%)$ \\
Visual improvement & $15(29.4 \%)$ & $5(25.0 \%)$ & $10(58.8 \%)$ & $30(34.1 \%)$ \\
EDH & $1(2.0 \%)$ & $1(5.0 \%)$ & $1(5.9 \%)$ & $3(3.4 \%)$ \\
SDH & $2(3.9 \%)$ & $2(10.0 \%)$ & 0 & $4(4.5 \%)$ \\
Hydrocephalus & $1(2.0 \%)$ & $1(5.0 \%)$ & 0 & $2(2.3 \%)$ \\
CSF leak & $3(5.9 \%)$ & 0 & $1(5.9 \%)$ & $4(4.5 \%)$ \\
Abscess & $2(3.9 \%)$ & 0 & 0 & $2(2.3 \%)$ \\
\hline
\end{tabular}

Adverse Events

The total rate of complications requiring surgical intervention was 17.0\% (OGM 17.6\%, PSM 20\%, and TSM 11.8\%). Postoperative epidural hematoma (EDH) necessitating revision surgery appeared in $3.4 \%$ of patients (OGM 2.0\%, PSM 5.0\%, and TSM 5.9\%). Subdural hematoma (SDH) occurred in $4.5 \%(4 / 88)$ of patients (OGM 3.9\% and PSM 10.0\%). All EDHs and SDHs appeared in patients who underwent a prior pterional approach. Furthermore, 2.3\% of patients (OGM 2.0\%, PSM 5.0\%) developed a cerebrospinal fluid (CSF) shunt-dependent hydrocephalus. CSF leaks appeared in $4.6 \%$ of patients (OGM 5.9\%, TSM 5.9\%). One patient with OGM and TSM was operated upon via a pterional approach, one OGM patient was operated upon via a bifrontal approach, and another patient with OGM was operated upon via a frontal interhemispheric approach. Tumor volume was a significant risk factor for developing a CSF leak $(p=0.002)$ and hydrocephalus $(p<0.001)$. Postoperative abscesses appeared in $2.3 \%$ of patients (OGM $3.9 \%$ ) (Figure 1).
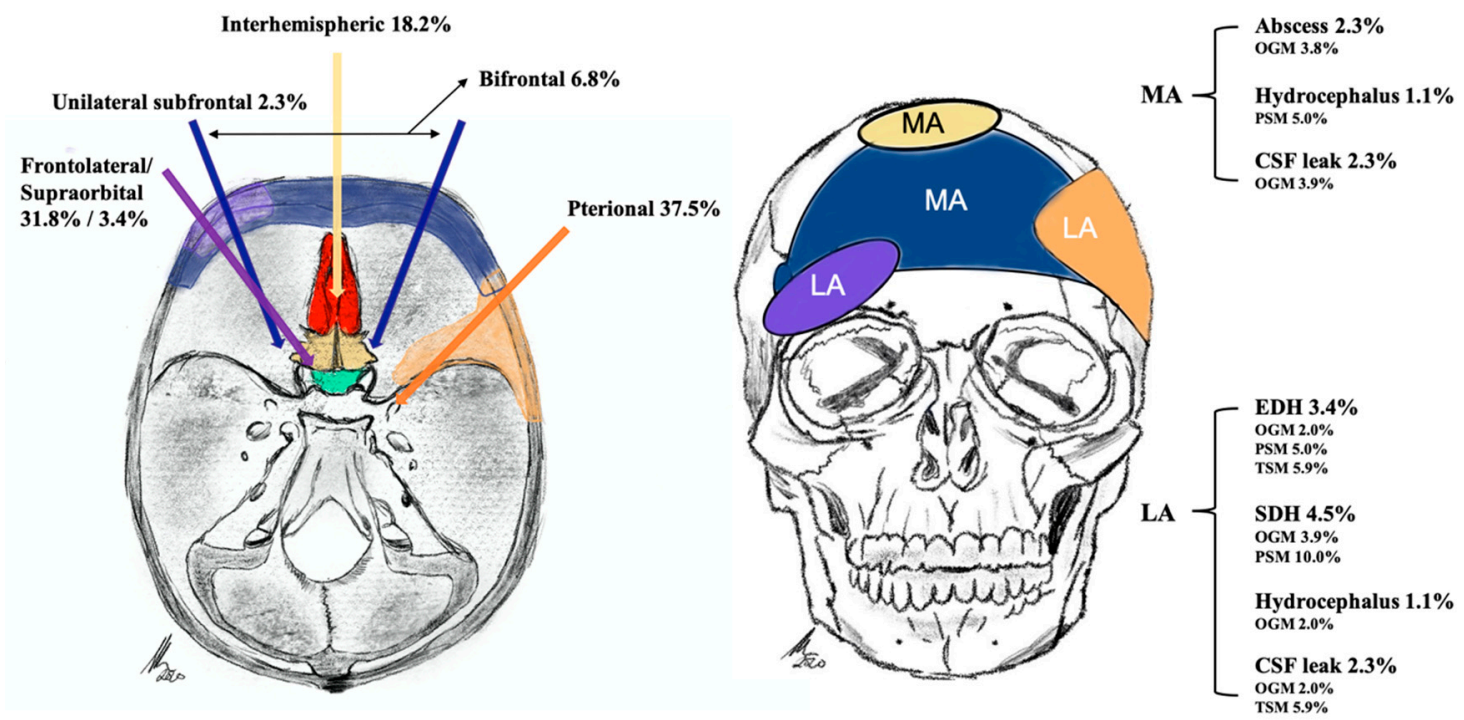

Figure 1. Illustration of performed approaches, angle of exposure, and approach-related complications, dichotomized into median (MA) and lateral (LA) approaches.

\subsection{Median vs. Lateral Approach Regarding Operative Characteristics}

Logistic regression analysis showed various significant parameters if a lateral approach was chosen: preoperative tumor volume (OR 0.966; 95\% CI, 0.942-0.990, $p=0.006$ ), preoperative KPSS (OR 1.051; 95\% CI, 1.008-1.096, $p=0.020$ ), a PSM (OR 15.607; 95\% CI, 1.940-125.572, $p=0.001$ ), a TSM (OR 6.160; 95\% CI, 1.275-29.765, $p=0.024$ ), an OGM (OR 0.034; 95\% CI, 0.000-0.6398, $p=0.001$ ), preoperative anosmia/hyposmia (OR 0.206; $95 \% \mathrm{CI}, 0.760-0.557, p=0.002)$, perifocal edema (OR 0.369; $95 \%$ CI $1.378-0.988, p=0.047$ ), an affection of the ethmoid bone (OR 0.169; 95\% CI, $0.387-0.741, p=0.018$ ), an infiltration of the cribriform plate (OR $0.232 ; 95 \% \mathrm{CI}, 0.081-0.662, p=0.006)$, tumor proximity to 
the anterior circulation (ACOMA, ACA) (OR 0.084; 95\% CI, 0.008-0.871, $p=0.038$ ) and infiltration of orbit/optic nerve/chiasmatic structures (OR 41.118; 95\% CI, 1.503-1124.872, $p=0.028$ ).

Based on these and previously mentioned findings, we developed an algorithm for choosing median and lateral approaches (Figure 2).

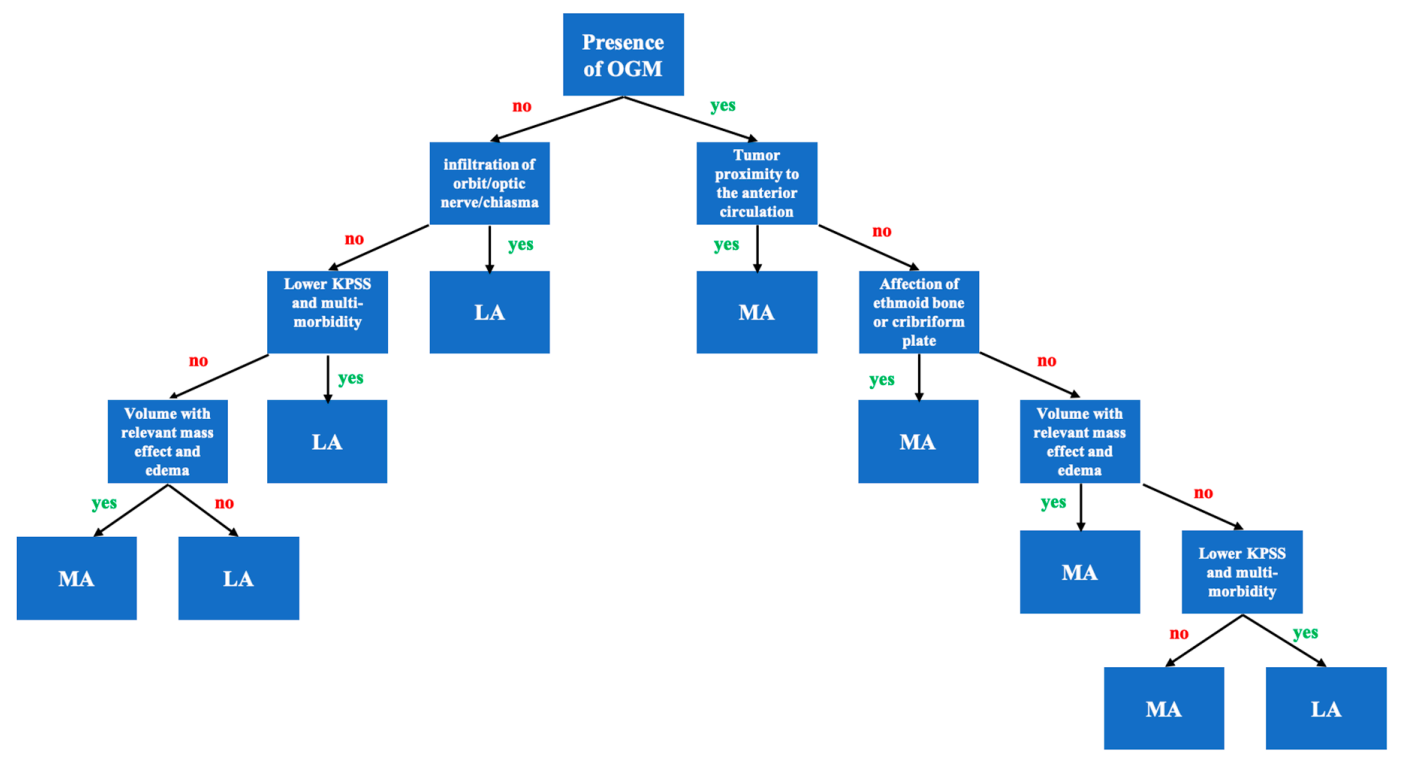

Figure 2. Proposed decision-making algorithm for targeting olfactory groove (OGM), planum sphenoidale (PSM) or tuberculum sellae meningiomas (TSM) based on our surgical experience, findings and statistical analysis. (MA = median approach; LA = lateral approach).

\subsection{Exemplary Cases}

\subsubsection{Exemplary Case One}

A 41-year-old female patient presented with a headache and right visual decline. A A preoperative axial and B sagittal T1-weighted and gadolinium-enhanced MRI showed a TSM with chiasma and optic nerve affection. A C postoperative sagittal and D axial MRI control indicated a complete Simpson grade-I resection. The resection was performed through a pterional approach. Postoperatively, the patient did not recover from the $0.8 \mathrm{c}$. visual decline but remained stable during follow-up (Figure 3).

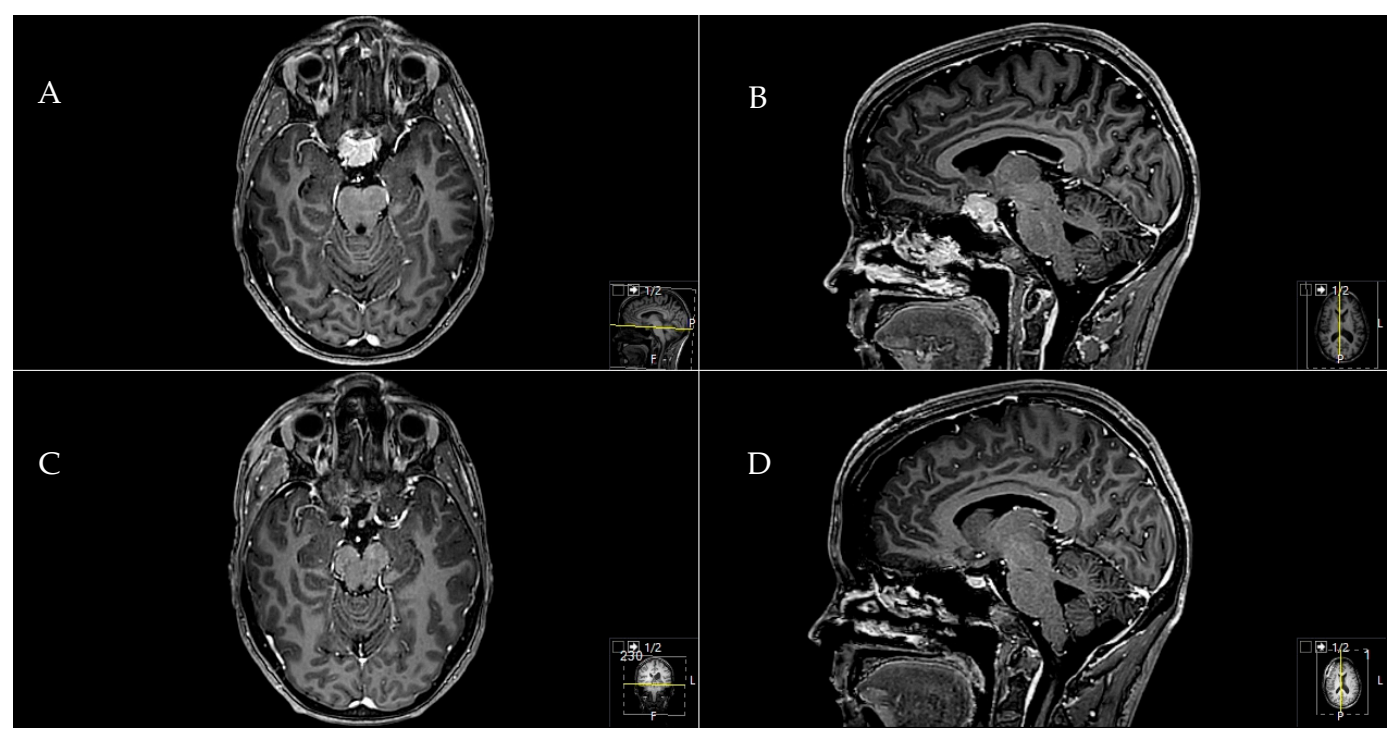

Figure 3. Exemplary case of a TSM with visual affection. 


\subsubsection{Exemplary Case Two}

A 47-year-old male patient presented with a headache, hyposmia, and lingering visual deficits. A A preoperative sagittal and B axial T1-weighted gadolinium-enhanced MRI showed an OGM with significant mass effect and perifocal edema. The preoperative tumor volume was $75.1 \mathrm{~cm}^{3}$. A C postoperative sagittal and D axial MRI control indicated a complete Simpson grade-I resection with no residual tumor. The resection was performed through a frontal interhemispheric approach. Postoperatively, the patient recovered from psychomotoric and visual decline. A galea-periosteum flap was used to prevent a postoperative CSF leak (Figure 4).

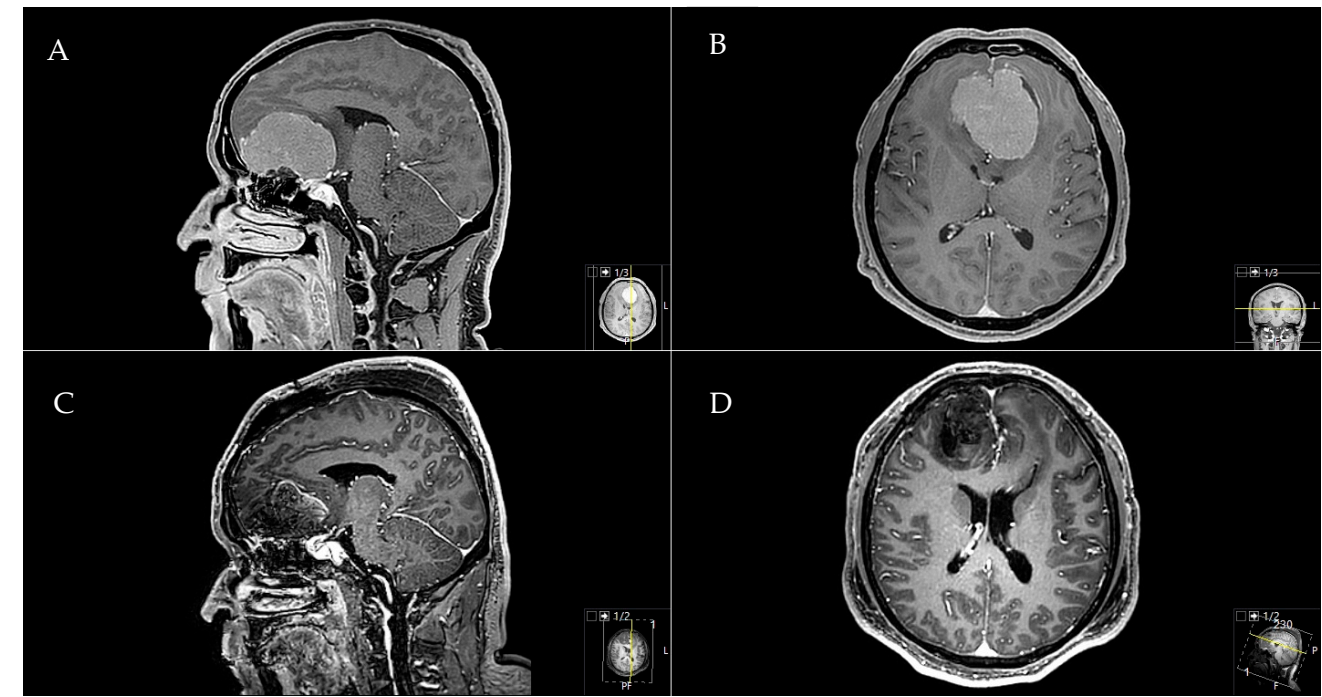

Figure 4. Exemplary case of a huge OGM.

\subsubsection{Exemplary Case Three}

A 68-year-old male patient presented with headache and fast progressing visual deficits. A A preoperative axial and B sagittal T1-weighted gadolinium-enhanced MRI showed a calcified PSM with mass effect. A C postoperative axial and D sagittal MRI control indicated a complete Simpson grade-I resection with no residual tumor. The resection was performed through a pterional approach. Postoperatively, the patient recovered from the visual deficits (Figure 5).

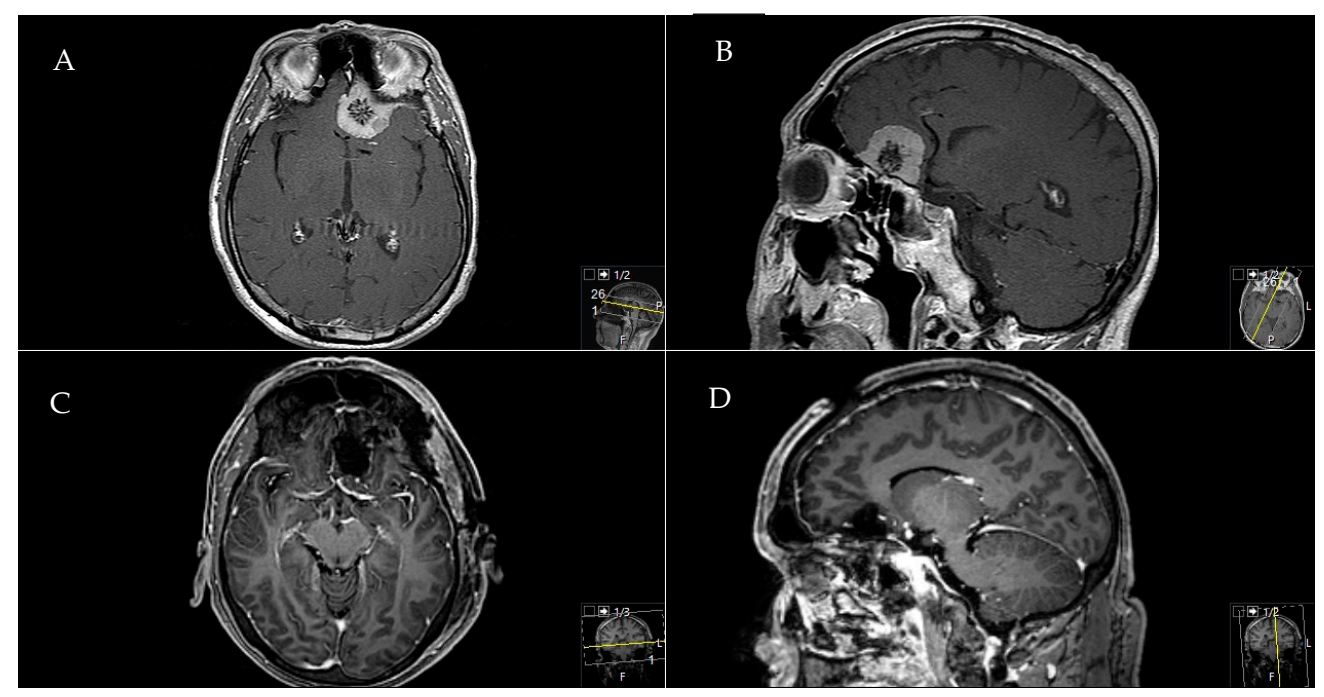

Figure 5. Exemplary case of a calcified PSM. 


\section{Discussion}

In the present series, clinical and anatomical findings and the clinical follow-up were evaluated. Good clinical outcomes and high rates of Simpson I and II resections were achieved using standard skull-base approaches (Figures 1-3). The treatment strategy in anterior skull-base midline meningiomas should always respect an individual's anatomy, clinical presentation, and baseline characteristics. To help choose an appropriate approach, we propose a decision tree based on data from the present cohort. We believe the surgeon's main choice is whether to access the lesion via a median or lateral approach. To do so, slight individualizations of the common "work horse" approaches (such as the midline or pterional craniotomies) can achieve good clinical results and resection extent [1,11-14]. This philosophy flattens the learning curve, harbors fewer risks than complex approaches, and might save surgical time compared to that used in complex approach preparation for the actual tumor resection.

\subsection{The Median Approaches}

In the present cohort, median approaches were mainly chosen for OGMs and PSMs. Median approaches might facilitate the intraoperative orientation because the anatomy is visualized in a straight line. The classic bifrontal approach allows good devascularization in OGM or PSM cases [7,8,14-19], but it makes visualizing the ACOM complex and optic nerves laborious, because they might be hidden behind tumor masses, thus rendering this approach less suitable for TSM patients $[13,17,20]$. Therefore, the interhemispheric approach might optimize control of the anterior vascular structures and optic nerves, which is why we advocate this technique. Preserving superficial veins is of utmost importance to reduce intra- and postoperative swelling of the frontal lobe. Adopted from the classic bifrontal approach, the transbasal/subfrontal approach enables superior devascularization of OGMs and PSMs with less brain retraction $[6,7,17,21-23]$. Nevertheless, the risk for CSF leakage might increase $[4,7,17,24-28]$. We also experienced this in patients with OGMs (Table 3). As an extension, the frontobasal interhemispheric approach via the interhemispheric fissure's broader anatomical corridor might reduce frontal lobe retractions [7,23,29-32]. This technique offers a better visualization if the bony skull base is infiltrated [7,23,29-32].

\subsection{The Lateral Approaches}

The majority of patients $(72.7 \%$ [64/88]) operated upon in the present cohort underwent a lateral approach. This group included pterional, frontolateral, and smaller supraorbital approaches. Lateral craniotomies allow excellent and quick visualization of the anterior circulation on both sides as well as superior access to the optic nerve, chiasm, and pituitary complex [1,11-14,17]. The classic pterional approach $[11,12,16]$ offers a wide visualization of the parenchyma and the skull base, especially for lesions extending more laterally. However, the supraorbital approach is a minimally invasive alternative for more median-located lesions and for the ACOM complex [33,34]. Extradural preparation of the anterior clinoid process is advocated in cases with a more lateral TSM. For intradural preparation, meticulous drilling and irrigation is necessary to avoid heat-related damage to optic structures $[4,6,17]$. Various modifications of these "work horses" in skull-base surgery have been published and have trended in recent years [35-39].

\subsection{Extent of Resection}

For the vast majority of patients in this manuscript, an extensive resection was achieved according to the Simpson grading (96.6\% achieved grades I and II). Comparable to Bassiouni et al., we reached significantly more Simpson grade-I results in OGMs (51.0\% vs. $42.9 \%$ ), even with infiltration of the anterior skull base or extension into the ethmoids or nasal cavity [19]. The resection extent did not correlate with initial tumor size in Bassiouni et al.'s series, indicating that a proper surgical approach may enable a total resection, irrespective of tumor extension. When the meningioma invades the frontal skull base, a median approach was chosen to optimize the visualization angle. Furthermore, 
preparing a wide frontal extracranial opening enables a large periostal flap for skull-base reconstruction or the use of a spilt bone graft technique.

\subsection{Clinical Outcome}

Clinical outcomes after resections of anterior skull-base midline meningiomas showed overall good results. A common main goal of resection is removing mostly benign tumor masses with slight or no neurological symptoms, so avoiding postoperative neurological deficits is of utmost importance. Our numbers align with prior reports, and comparisons of these individual skull-base lesions can be difficult $[2,4,6-8,14,16,17,26]$. Interestingly, clinical outcomes did not substantially differ when comparing the "classic" approaches in this cohort to more complex skull-base approaches. These differences bring into question their routine use and use for selected cases [9,21,40-42]. In the present cohort, interhemispheric and subfrontal approaches are associated with higher rates of relevant cognitive disorders after surgery, as controversially discussed in earlier publications [4,43-45]. Optic nerve and chiasm affections are often more safely handled from a lateral approach $[13,16,19]$. In the present cohort, postoperative visual improvement occurred in $35 \%$ of cases. Especially tumorous involvement of the orbit/optic structures emphasizes the posterior view's advantage via the lateral approach, and the optic canal decompression can be done intra- or extradurally. The approach can occur from the side with more severely damaged optic structures. Regarding PSMs and TSMs, no clear consensus exists regarding the optimal approach. The frontolateral approach reportedly has a high rate of visual improvement (77.8\%) [6].

Regarding huge infiltrating OGMs, preserving olfaction remains hardly possible. Various solutions have not substantially improved the outcome [4,7-9,26,29,46-48]. We did not see any postoperative improvement in our series.

In contrast, the outlook for visual improvement is better. In the present cohort, $25 \%$ of patients with PSM and $58.8 \%$ of patients with TSM had improved visual parameters, which aligns with prior reports on optic decompression $[4,6,16,17,35-37,48]$.

\subsection{Adverse Events}

Comparing adverse events other than neurological deficits (see clinical outcomes), we identified a clear trend toward higher postoperative complication rates—especially for SDH and EDH—in lateral approaches. On the other hand, CSF leakage appeared more often in patients who underwent median approaches for OGMs, but still at rates comparable to previous reports $[4,7,17,24-26]$. This seems explicable, as OGMs infiltrating the thin cribriform plate tend to result in more CSF leaks and are regularly attacked via median approaches $[27,28]$. Overall surgical site infection rates are low $(2.3 \%$ in the present cohort) and may be provoked by the larger tumor volume and longer surgery durations in our cohort $[8,9,24,27,28,49]$. Therefore, shorter surgery via a simple approach might impact infection rates, but this cannot be proven in this study.

\subsection{Choosing a Suitable Approach}

Based on the present cohort, we developed an algorithm to choose between median and lateral approaches. The most important factor is an OGM $(p=0.001)$ favoring a median approach or a relevant tumor mass effect $(p=0.006)$ requiring bilateral exposure or a direct perpendicular viewpoint. A lateral approach might be suitable to spare the anterior vascular complex or in the absence of bony arrosion of the skull base, in the absence of significant parenchymal oedema or in the presence of lower KPSS $(p=0.020)$. In more lateral lesions, such as TSMs and PSMs, a lateral approach is advocated. The median approach might work for patients without affection of the optic nerve or with a higher baseline KPSS and substantial parenchymal oedema.

Our findings suggest that a lateral approach's advantages are emphasized in cases of PSM and TSM tumorous involvement of the optic structures. Early visualization of the visual apparatus is possible, brain retraction is reduced, and the exposure and angle of view are commonly known. 
We do not differentiate between several techniques of median or lateral approaches and advocate using the most feasible approach according to institutional experience, habit and, of course, a tailored choice of approach for each case. Our proposed algorithm may serve as an additional tool, and we recommend keeping techniques as simple as possible.

\subsection{Study Limitations}

As a retrospective case series, we cannot draw causalities regarding clinical outcomes. Nevertheless, we implemented a detailed clinical examination, including scores on functional performance, and a standardized follow-up protocol based on a certified neurooncological board's clinical workflow.

In addition, one should note that the impact of this manuscript could be seen as limited, as surgical approaches have been selected on an individual patient basis considering tumor and patient-related factors. As we decided to mainly focus on classic transcranial approaches and its technical considerations in order to obtain best oncological outcome, we did not include endoscopic approaches in our analysis. This point has to be discussed and may also be compared with classic approaches in future studies as minimal-invasive techniques are on the rise. In addition, the role of radiosurgery is often considered in treatment decision making of skull base meningiomas, especially in cases of patients not suitable for surgery or in case of recurrence or malignancy. Surgeon experience, prior training, and learning curves have to be taken into consideration as well.

In addition to its retrospective nature, the analyzed patient collective suffers from certain heterogeneities. For example, different types of meningiomas may create inhomogeneity. The number of patients with TSM and PSM was limited to 17 and 20, respectively, out of 88 total patients, which could lead to variability in the results. We included them in the analysis because all aspects of midline meningiomas of the anterior skull base should be reflected and because basic surgical techniques are similar for TSM and for PSM.

\section{Materials and Methods}

\subsection{Study Design}

We performed an observational retrospective single-center study. Patients who underwent surgery for midline meningiomas via transcranial approaches between June 2007 and January 2020 were included. Entities other than meningiomas were excluded from the analysis. The local ethics committee of the Technical University of Munich's School of Medicine approved our study (231/20 S-EB). We conducted it in accordance with the ethical standards of the 1964 Declaration of Helsinki and its later amendments [50].

\subsection{Outcome Parameters}

The clinical records of patients who underwent surgery for a midline meningioma were analyzed regarding their preoperative neurological symptoms, Karnofsky Performance Status Scale (KPSS), new postoperative neurological deficits, postoperative complications, and re-interventions. OGM, PSM, and TSM were summed as midline meningiomas. The approaches used were dichotomized into lateral (pterional/frontolateral/supraorbital) and median (interhemispheric, bifrontal, subfrontal) approaches. The extent of resection was defined by comparing pre- and postoperative $3.0 \mathrm{~T}$ cranial magnetic resonance imaging (MRI) using $\mathrm{T} 1 \pm$ contrast agent sequences by manual volumetric segmentation, using the Origin ${ }^{\circledR}$ software (Brainlab, version 3.1, Brainlab AG, Munich, Germany). Preoperative signs of calcification (in computed tomography) and perifocal oedema (3.0T MRI T2 sequences) were also noted. 


\subsection{Statistics}

Statistical analysis was performed using the software package STATA version 13.1 (2011, StataCorp, College Station, Lakeway Drive, TX, USA). Normal distributions were assumed according to the central limit theorem. An unpaired 2-tailed Student's $t$ test was used to compare the significance of the means between two groups and were corrected for alpha error using the Holm-Bonferroni method. For the categorical variables, unpaired Mann-Whitney U tests were used to compare two samples. Proportions and group differences were analyzed with chi-square statistics. Additionally, logistic regression models with adjustment for potential predictive factors were calculated. Odds ratios with $95 \%$ confidence intervals $(95 \% \mathrm{CI})$ were estimated. $p \leq 0.05$ was considered significant.

\subsection{Ethics Approval}

The local ethics committee of Technical University Munich, School of Medicine, approved our study (231/20 S-EB). We conducted it in accordance with the ethical standards of the 1964 Declaration of Helsinki and its later amendments [50].

\section{Conclusions}

Even in large tumors, high rates of total tumor resection with few complications were achieved with simple approaches, allowing easy access with sufficient exposure. Considering the operative morbidity and functional outcome, the median approach provides satisfactory results in OGM cases, and lateral approaches enabled sufficient exposure of the optic apparatus in PSM and TSM cases. Proposing a simple decision-making algorithm for determining the best approach, the authors found satisfactory outcomes are possible for anterior skull-base midline meningiomas.

Author Contributions: Conceptualization, A.K.A., M.B., J.G.; methodology, A.K.A., M.B.; software, A.K.A.; validation, A.K.A., J.G., M.B.; formal analysis, A.K.A., M.B.; investigation, A.K.A.; resources, A.K.A.; data curation, A.K.A., M.B.; writing—original draft preparation, A.K.A.; writing—review and editing, A.K.A., M.B., P.K., A.W., N.L., A.H., B.W., B.M., C.N., J.G.; visualization, A.K.A.; supervision, B.M., C.N., J.G.; project administration, B.M., J.G. All authors have read and agreed to the published version of the manuscript.

Funding: This research received no external funding.

Conflicts of Interest: Jens Gempt and Bernhard Meyer (BM) work as consultants for Brainlab (Brainlab AG, Feldkirchen). In addition, BM works as a consultant for Medtronic, Spineart, Icotec, Relievant and Depuy/Synthes, as a member of their advisory boards. Furthermore, BM reports financial relationships with Medtronic, Ulrich Medical, Brainlab, Spineart, Icotec, Relievant and Depuy/Synthes. He received personal fees and research grants for clinical studies from Medtronic, Ulrich Medical, Brainlab, Icotec and Relievant. All of this happened independently of the submitted work. BM receives royalties and holds the patent for Spineart. All of the named potential conflicts of interest are unrelated to this study. There are no further conflicts of interest regarding the authors.

\section{References}

1. Mortazavi, M.M.; Brito da Silva, H.; Ferreira, M., Jr.; Barber, J.K.; Pridgeon, J.S.; Sekhar, L.N. Planum Sphenoidale and Tuberculum Sellae Meningiomas: Operative Nuances of a Modern Surgical Technique with Outcome and Proposal of a New Classification System. World Neurosurg. 2016, 86, 270-286. [CrossRef]

2. Nanda, A.; Bir, S.C.; Maiti, T.K.; Konar, S.K.; Missios, S.; Guthikonda, B. Relevance of Simpson grading system and recurrence-free survival after surgery for World Health Organization Grade I meningioma. J. Neurosurg. 2017, 126, 201-211. [CrossRef] [PubMed]

3. Komotar, R.J.; Starke, R.M.; Raper, D.M.; Anand, V.K.; Schwartz, T.H. Endoscopic endonasal versus open transcranial resection of anterior midline skull base meningiomas. World Neurosurg. 2012, 77, 713-724. [CrossRef] [PubMed]

4. Nanda, A.; Maiti, T.K.; Bir, S.C.; Konar, S.K.; Guthikonda, B. Olfactory Groove Meningiomas: Comparison of Extent of Frontal Lobe Changes after Lateral and Bifrontal Approaches. World Neurosurg. 2016, 94, $211-221$. [CrossRef] [PubMed] 
5. Nakamura, M.; Struck, M.; Roser, F.; Vorkapic, P.; Samii, M. Olfactory groove meningiomas: Clinical outcome and recurrence rates after tumor removal through the frontolateral and bifrontal approach. Neurosurgery 2008, 62, 1224-1232. [CrossRef] [PubMed]

6. Nakamura, M.; Roser, F.; Struck, M.; Vorkapic, P.; Samii, M. Tuberculum sellae meningiomas: Clinical outcome considering different surgical approaches. Neurosurgery 2006, 59, 1019-1028, discussion 1019-1028. [CrossRef]

7. Obeid, F.; Al-Mefty, O. Recurrence of olfactory groove meningiomas. Neurosurgery 2003, 53, 534-542, discussion 533-542. [CrossRef] [PubMed]

8. Sekhar, L.N.; Nanda, A.; Sen, C.N.; Snyderman, C.N.; Janecka, I.P. The extended frontal approach to tumors of the anterior, middle, and posterior skull base. J. Neurosurg. 1992, 76, 198-206. [CrossRef] [PubMed]

9. Liu, J.K.; Silva, N.A.; Sevak, I.A.; Eloy, J.A. Transbasal versus endoscopic endonasal versus combined approaches for olfactory groove meningiomas: Importance of approach selection. Neurosurg. Focus 2018, 44, E8. [CrossRef]

10. Ottenhausen, M.; Rumalla, K.; Alalade, A.F.; Nair, P.; Corte, E.L.; Younus, I.; Forbes, J.A.; Nsir, A.B.; Banu, M.A.; Tsiouris, A.J.; et al. Decision-making algorithm for minimally invasive approaches to anterior skull base meningiomas. Neurosurg. Focus 2018, 44, E7. [CrossRef]

11. Yaşargil, M.G. Microneurosurgery: Microsurgery of CNS Tumors: Instrumentation and Equipment, Laboratory, Training, Surgical Approaches, Strategies, Tactics and Techniques, Surgery and Results of Extrinsic and Intrinsic Tumors, Interventional Neuroradiology, Neuroanesthesia, Complications; Thieme: New York, NY, USA, 1996.

12. Hassler, W.; Zentner, J. Pterional Approach for Surgical Treatment of Olfactory Groove Meningiomas. Neurosurgery 1989, 25, 942-947. [CrossRef] [PubMed]

13. Bitter, A.D.; Stavrinou, L.C.; Ntoulias, G.; Petridis, A.K.; Dukagjin, M.; Scholz, M.; Hassler, W. The Role of the Pterional Approach in the Surgical Treatment of Olfactory Groove Meningiomas: A 20-year Experience. J. Neurol. Surg. Part B Skull Base 2013, 74, 97-102. [CrossRef]

14. Aguiar, P.H.; Tahara, A.; Almeida, A.N.; Simm, R.; Silva, A.N.; Maldaun, M.V.; Panagopoulos, A.T.; Zicarelli, C.A.; Silva, P.G. Olfactory groove meningiomas: Approaches and complications. J. Clin. Neurosci. 2009, 16, 1168-1173. [CrossRef]

15. Al-Mefty, O.; Holoubi, A.; Rifai, A.; Fox, J.L. Microsurgical removal of suprasellar meningiomas. Neurosurgery 1985, 16, 364-372. [CrossRef]

16. Schick, U.; Hassler, W. Surgical management of tuberculum sellae meningiomas: Involvement of the optic canal and visual outcome. J. Neurol. Neurosurg. Psychiatry 2005, 76, 977-983. [CrossRef]

17. Nakamura, M.; Struck, M.; Roser, F.; Vorkapic, P.; Samii, M. Olfactory groove meningiomas: Clinical outcome and recurrence rates after tumor removal through the frontolateral and bifrontal approach. Neurosurgery 2007, 60, 844-852. [CrossRef] [PubMed]

18. Mukherjee, S.; Thakur, B.; Corns, R.; Connor, S.; Bhangoo, R.; Ashkan, K.; Gullan, R. Resection of olfactory groove meningioma-A review of complications and prognostic factors. Br. J. Neurosurg. 2015, 29, 685-692. [CrossRef] [PubMed]

19. Bassiouni, H.; Asgari, S.; Stolke, D. Olfactory groove meningiomas: Functional outcome in a series treated microsurgically. Acta Neurochir. (Wien) 2007, 149, 109-121, discussion 121. [CrossRef]

20. Kempe, L.G.; VanderArk, G.D. Anterior communicating artery aneurysms. Gyrus rectus approach. Neurochirurgia (Stuttg) 1971, 14, 63-70. [CrossRef]

21. Feiz-Erfan, I.; Spetzler, R.F.; Horn, E.M.; Porter, R.W.; Beals, S.P.; Lettieri, S.C.; Joganic, E.F.; Demonte, F. Proposed classification for the transbasal approach and its modifications. Skull Base 2008, 18, 29-47. [CrossRef]

22. Spektor, S.; Valarezo, J.; Fliss, D.M.; Gil, Z.; Cohen, J.; Goldman, J.; Umansky, F. Olfactory groove meningiomas from neurosurgical and ear, nose, and throat perspectives: Approaches, techniques, and outcomes. Neurosurgery 2005, 57, 268-280, discussion 268-280. [CrossRef]

23. Dehdashti, A.R.; de Tribolet, N. Frontobasal interhemispheric trans-lamina terminalis approach for suprasellar lesions. Neurosurgery 2008, 62, 1233-1239. [CrossRef] [PubMed]

24. Raveh, J.; Turk, J.B.; Ladrach, K.; Seiler, R.; Godoy, N.; Chen, J.; Paladino, J.; Virag, M.; Leibinger, K. Extended anterior subcranial approach for skull base tumors: Long-term results. J. Neurosurg. 1995, 82, 1002-1010. [CrossRef] [PubMed]

25. Kurtsoy, A.; Menkü, A.; Tucer, B.; Oktem, I.; Akdemir, H.; Koç, R. Transbasal approaches: Surgical details, pitfalls and avoidances. Neurosurg. Rev. 2004, 27, 267-273. [CrossRef] 
26. Nanda, A.; Patra, D.P.; Savardekar, A.R.; Mohammed, N.; Narayan, V.; Bir, S.C. Surgery of Tuberculum Sellae Meningioma: A Technical Purview on Pterional Approach. J. Neurol. Surg. B Skull Base 2018, 79, S265-S266. [CrossRef]

27. Chandler, J.P.; Silva, F.E. Extended transbasal approach to skull base tumors. Technical nuances and review of the literature. Oncology (Williston Park) 2005, 19, 913-919, discussion 915-923, 929.

28. Fliss, D.M.; Zucker, G.; Cohen, A.; Amir, A.; Sagi, A.; Rosenberg, L.; Leiberman, A.; Gatot, A.; Reichenthal, E. Early outcome and complications of the extended subcranial approach to the anterior skull base. Laryngoscope 1999, 109, 153-160. [CrossRef] [PubMed]

29. Ganna, A.; Dehdashti, A.R.; Karabatsou, K.; Gentili, F. Fronto-basal interhemispheric approach for tuberculum sellae meningiomas; long-term visual outcome. Br. J. Neurosurg. 2009, 23, 422-430. [CrossRef] [PubMed]

30. Dehdashti, A.R.; de Tribolet, N. Frontobasal interhemispheric trans-lamina terminalis approach for suprasellar lesions. Neurosurgery 2005, 56, 418-424. [CrossRef]

31. Suzuki, J.; Mizoi, K.; Yoshimoto, T. Bifrontal interhemispheric approach to aneurysms of the anterior communicating artery. J. Neurosurg. 1986, 64, 183-190. [CrossRef]

32. Shibuya, M.; Takayasu, M.; Suzuki, Y.; Saito, K.; Sugita, K. Bifrontal basal interhemispheric approach to craniopharyngioma resection with or without division of the anterior communicating artery. J. Neurosurg. 1996, 84, 951-956. [CrossRef]

33. Esposito, G.; Dias, S.F.; Burkhardt, J.-K.; Fierstra, J.; Serra, C.; Bozinov, O.; Regli, L. Selection Strategy for Optimal Keyhole Approaches for Middle Cerebral Artery Aneurysms: Lateral Supraorbital Versus Minipterional Craniotomy. World Neurosurg. 2019, 122, e349-e357. [CrossRef]

34. Banu, M.A.; Mehta, A.; Ottenhausen, M.; Fraser, J.F.; Patel, K.S.; Szentirmai, O.; Anand, V.K.; Tsiouris, A.J.; Schwartz, T.H. Endoscope-assisted endonasal versus supraorbital keyhole resection of olfactory groove meningiomas: Comparison and combination of 2 minimally invasive approaches. J. Neurosurg. 2016, 124, 605-620. [CrossRef]

35. Goel, A.; Bhaganagare, A.; Shah, A.; Kaswa, A.; Rai, S.; Dharurkar, P.; Gore, S. Olfactory groove meningiomas: An analysis based on surgical experience with 129 cases. Neurol. India 2018, 66, 1081-1086. [CrossRef]

36. Goel, A.; Muzumdar, D.; Desai, K.I. Tuberculum sellae meningioma: A report on management on the basis of a surgical experience with 70 patients. Neurosurgery 2002, 51, 1358-1363, discussion 1354-1363. [CrossRef]

37. Chokyu, I.; Goto, T.; Ishibashi, K.; Nagata, T.; Ohata, K. Bilateral subfrontal approach for tuberculum sellae meningiomas in long-term postoperative visual outcome. J. Neurosurg. 2011, 115, 802-810. [CrossRef]

38. Ohta, K.; Yasuo, K.; Morikawa, M.; Nagashima, T.; Tamaki, N. Treatment of tuberculum sellae meningiomas: A long-term follow-up study. J. Clin. Neurosci. 2001, 8 (Suppl. 1), 26-31. [CrossRef]

39. Arai, H.; Sato, K.; Okuda, O.; Miyajima, M.; Hishii, M.; Nakanishi, H.; Ishii, H. Transcranial transsphenoidal approach for tuberculum sellae meningiomas. Acta Neurochir. (Wien) 2000, 142, 751-756, discussion 756-757. [CrossRef]

40. Liu, J.K.; Watanabe, K. Modified One-Piece Extended Transbasal Approach for Endoscopic-Assisted Microsurgical Resection of Tuberculum Sellae Meningioma: Operative Video and Technical Nuances. J. Neurol. Surg. B Skull Base 2018, 79, S213-S214. [CrossRef] [PubMed]

41. Effendi, S.T.; Rao, V.Y.; Momin, E.N.; Cruz-Navarro, J.; Duckworth, E.A. The 1-piece transbasal approach: Operative technique and anatomical study. J. Neurosurg. 2014, 121, 1446-1452. [CrossRef] [PubMed]

42. Tomasello, F.; Angileri, F.F.; Grasso, G.; Granata, F.; De Ponte, F.S.; Alafaci, C. Giant olfactory groove meningiomas: Extent of frontal lobes damage and long-term outcome after the pterional approach. World Neurosurg. 2011, 76, 311-317. [CrossRef]

43. Lu, Z.F. Resection of suprasellar meningioma through interhemispheric approach. J. Craniofac. Surg. 2014, 25, 1302-1304. [CrossRef]

44. Joseph, V.; Chacko, A.G. Suprabrow minicraniotomy for suprasellar tumours. Br. J. Neurosurg. 2005, 19 , 33-37. [CrossRef] [PubMed]

45. Balanzar, G.G. Giant Olfactory Groove Meningiomas: Extent of Frontal Lobes Damage and Long-Term Outcome after the Pterional Approach. World Neurosurg. 2011, 76, 255-256. [CrossRef]

46. Dedeciusova, M.; Svoboda, N.; Benes, V.; Astl, J.; Netuka, D. Olfaction in Olfactory Groove Meningiomas. J. Neurol. Surg. A Cent. Eur. Neurosurg. 2020, 81, 310-317. [CrossRef]

47. Mielke, D.; Mayfrank, L.; Psychogios, M.N.; Rohde, V. The anterior interhemispheric approach: A safe and effective approach to anterior skull base lesions. Acta Neurochir. (Wien) 2014, 156, 689-696. [CrossRef] 
48. Curey, S.; Derrey, S.; Hannequin, P.; Hannequin, D.; Freger, P.; Muraine, M.; Castel, H.; Proust, F. Validation of the superior interhemispheric approach for tuberculum sellae meningioma: Clinical article. J. Neurosurg. 2012, 117, 1013-1021. [CrossRef] [PubMed]

49. Georgantopoulou, A.; Hodgkinson, P.D.; Gerber, C.J. Cranial-base surgery: A reconstructive algorithm. Br. J. Plast. Surg. 2003, 56, 10-13. [CrossRef]

50. World Medical Association Declaration of Helsinki: Ethical principles for medical research involving human subjects. JAMA 2013, 310, 2191-2194. [CrossRef]

Publisher's Note: MDPI stays neutral with regard to jurisdictional claims in published maps and institutional affiliations.

(C) 2020 by the authors. Licensee MDPI, Basel, Switzerland. This article is an open access article distributed under the terms and conditions of the Creative Commons Attribution (CC BY) license (http://creativecommons.org/licenses/by/4.0/). 